\title{
DIALÉCTICA, DIAPORÉTICA Y SABER POSITIVO EN LA METAFÍSICA DE ARISTÓTELES
}

\author{
DIALECTIC, DIAPORETIC AND POSITIVE \\ KNOWLEDGE IN ARISTOTLES'S METAPHYSICS
}

\author{
Javier AgUiRre* \\ Universidad del País Vasco (San Sebastián)
}

\begin{abstract}
RESUMEN: El vínculo entre dialéctica y filosofía primera en la Metafísica de Aristóteles es estrecho, tal como lo muestra la importante presencia de procedimientos dialécticos en esa obra, entre los que se encuentran la revisión histórica, la demostración refutativa y el método diaporético. El método de la filosofía primera, no obstante, no puede identificarse con la dialéctica: si nos centramos en el procedimiento diaporético, puede comprobarse que la fase euporética constituye una fase no dialéctica del proceso, una fase que va mucho más allá de lo establecido por el procedimiento propiamente dialéctico del desarrollo diaporético. Ello queda patente en el análisis del desarrollo diaporético y de las soluciones ensayadas por Aristóteles a propósito de las aporías undécima y decimoquinta del libro Beta.
\end{abstract}

Palabras Clave: Dialéctica, aporía, diaporética, euporía, libro Beta.

ABSTRACT: The link between dialectics and first philosophy in Aristotle's Metaphysics is narrow, as it is showed by the important presence of dialectical procedures in this work,

* Trabajo que se enmarca dentro del proyecto de investigación I+D+I del Ministerio de Ciencia e Innovación con referencia FFI2009-11795, titulado La tradición gnoseológica aristotélica y los orígenes de la filosofía de la mente, cuyo investigador principal es el Dr. Miguel Candel Sanmartín, profesor de la Universidad de Barcelona (UB). 
among which we find the historical review, the peirastic demonstration and the diaporetic method. The method of the first philosophy, nevertheless, cannot be identified by the dialectics: if we centre on the diaporetic procedure, there can be verified that the euporetic phase constitutes a not dialectical phase of the process, a phase that goes far beyond of the established for the properly dialectical procedure of the diaporetic development. It remains clear in the analysis of the diaporetic development and of the solutions tested by Aristotle about the eleventh and the fifteenth apories of book Beta.

KEYWORDS: Dialectics, aporia, diaporetic, euporia, Book Beta.

El notable interés del mundo académico por la dialéctica aristotélica es un fenómeno que ha ocupado toda la segunda mitad del siglo XX y cuya intensidad no ha menguado con el cambio de siglo. Frente a la escasez de investigaciones desarrolladas durante la primera mitad, a partir de 1950 se despertó un renovado interés por el estudio de la dialéctica del Estagirita, tanto por describir su caracterización general como por definir su papel dentro de la obra global del filósofo ${ }^{1}$. Este interés culminó con la celebración de las importantes reuniones científicas de Oxford en $1963^{2}$ y Padua en $1967^{3}$. Por su trascendencia en el deba-

${ }^{1}$ A la primera mitad de siglo pertenecen, no obstante, los trabajos clásicos de L. M. Regis, L'opinion selon Aristote, París, 1935; y J. M. Le Blond, Logique et methode selon Aristote, París, 1939. Importantes aportaciones posteriores sobre la caracterización general de la dialéctica aristotélica son: E. Weil, «La place de la logique dans la pensée aristotèlicienne», Revue de Métaphisique et de morale, 1951, pp. 283-315; J. Croissant, «La dialectique chez Aristote», leído en 1951 pero publicado mucho después en J. Croissant, Études de philosophie ancienne, Bruselas, 1986, pp. 161-185; Ch. Perelman, «Dialectique et dialogue», Hermeneutik und Dialektik, Tubinga, 1952, pp. 77-83 y Rhétorique et philosophie. Pour une théorie de l'argumentation en Philosophie, París, 1958; C. A. Vianno, «La dialettica in Aristotele», Rivista di Filosofia 49, 1958, pp. 154-178; L. Lugarini, «Dialettica e filosofia in Aristotele», Il Pensiero 4, 1959, pp. 48-69 y Aristotele e l'idea della filosofia, Florencia, 1961 (2. ${ }^{a}$ ed. revisada: 1972); L. Sichirollo, Giutificazzioni della dialettica in Aristotele, Urbino, 1963 y Storicità della dialettica antica, Padua, 1965; sin olvidar la extensa y erudita introducción de J. Brunschwig a la edición de Topiques, París, 1967.

2 VV. AA., Aristotle on dialectic. The Topics. Proceedings of the third symposium aristotelicum, editado por G. E. L. Owen, Oxford, 1968.

3 VV. AA., L'attualitá della problematica aristotelica. Atti del convegno franco-italiano su Aristotele (Padova, 6-8 aprile 1967), Padova, 1970. 
te posterior sobre el papel de la dialéctica en la configuración de la filosofía primera aristotélica, tema del presente trabajo, merecen ser destacados los estudios de Aubenque ${ }^{4}$ y Berti ${ }^{5}$, ambos leídos durante la primera jornada del symposium de Padua. El tema no era nuevo; de hecho, el vínculo entre dialéctica y metafísica ya había sido tratado por los propios Aubenque ${ }^{6}$ y Berti ${ }^{7}$, y por el estudioso italiano Lugarini ${ }^{8}$, en una serie de trabajos que iba a constituir la referencia obligada en el estudio de las relaciones entre dialéctica y filosofía primera. A los trabajos citados se sumarían en los años posteriores nuevas e importantes aportaciones de numerosos especialistas ${ }^{9}$. En este contexto, merece ser destacado el tenaz y fructífero trabajo que sobre numerosos aspectos de la dialéctica antigua han realizado durante décadas los profesores Pierre Aubenque y Enrico Berti, trabajo al que hay que añadir el desarrollado más recientemente por la profesora Cristina Rossitto. Las decisivas aportaciones de estos tres autores han sido reu-

${ }^{4}$ P. Aubenque, «La dialectique chez Aristote», en L'attualitá..., op. cit., pp. 9-31.

5 E. Berti, «La dialettica in Aristotele», en L'attualitá..., op. cit., pp. 33-80; reimpreso en E. Berti, Studi aristotelici, L'Aquila, 1975, pp. 109-133.

${ }^{6}$ P. Aubenque, Le probleme de l'être chez Aristote, París, 1962.

7 E. Berti, E. L'Unitá del sapere in Aristotele, Padua, 1965.

8 L. Lugarini, 1959, op. cit. y 1961, op. cit. En el trabajo de 1961, Lugarini rebaja notablemente la importancia atribuida a la dialéctica en la constitución de la metafísica aristotélica. En la obra de Lugarini, además, merecen ser destacadas dos importantes aportaciones de cara al conocimiento general de la filosofía teorética aristotélica: 1) la constatación de que la apodíctica aristotélica no es tanto una metodología de búsqueda científica cuanto una metodología de exposición, es decir, de enseñanza o de comunicación de los contenidos de una ciencia ya completada. Esta tesis, asumida hoy en día por gran parte de los aristotelistas, fue retomada y desarrollada posteriormente por J. Barnes, "Aristotle's theory of demostration", Articles on Aristotle, Cambridge, 1975, pp. 65-87; y 2) la constatación de que los contenidos de la Metafísica pueden ser ordenados y estructurados en torno al esquema básico aporein-diaporein-euporein; de este esquema se sirven, entre otros, L. Couloubaritsis, «Dialectique et philosophie chez Aristote», Philosophia VIII-IX, 1978-1979, pp. 229-256; J. Barnes, "Aristotle and the methods of ethics», Revue internationale de Philosophie, XXXIV, 1980, pp. 490-511; E. Berti, «Aristote et la méthode dialectique du «Parmenide» de Platon, Revue internationale de Philosophie, XXXIV, 1980, pp. 341-358; y C. Rossitto «La dialettica e il suo ruolo nella Metafisica di Aristotele», Rivista de filosofia neo-scolastica, LXXXV, 1993, pp. 370-424.

9 Destacan las aportaciones de W. Leszl, Logic and metaphysics in Aristotle, Padua, 1970 y Aristotle's conception of ontology, Padua, 1975; L. Sichirollo, La dialettica, Milán, 1973, especialmente el capítulo IV, pp. 60-82, dedicado a la dialéctica aristotélica; J. D. G. Evans, Aristotlés conception of dialectic, Cambridge, 1977; L. Couloubaritsis, 1978-1979, op. cit.; T. H. Irwin, «Aristotle's discovery of Metaphysics», The review of metaphysics XXXI, 1976-1977, pp. 210-229; Barnes, J., 1980, op. cit. 
nidas en tres valiosísimos volúmenes de reciente publicación ${ }^{10}$. Teniendo siempre presente tan valioso material, la cuestión a la que se quiere responder en el presente trabajo es la siguiente: ¿qué papel juega el procedimiento de la diaporética en la conformación de su filosofía primera aristotélica? Y más concretamente, ¿qué es dialéctico y qué no lo es en el procedimiento diaporético aplicado en la Metafísica? Las respuestas elaboradas durante las últimas décadas han abandonado la tradicional exclusión mutua entre dialéctica y filosofía primera a favor de una unánime e incuestionable admisión de la dialéctica en la constitución de la filosofía primera. El debate, por consiguiente, se sitúa en valorar la importancia de la primera en la constitución de la segunda. De ello se trata en las siguientes páginas.

\section{El vínculo entre dialéctica y metafísica aristotélicas}

En «La dialectique chez Aristote», trabajo presentado en el symposium de Padua, Aubenque vuelve a defender el punto de vista ya desarrollado en Le problème de l'être chez Aristote, donde el autor argumentaba la identificación de hecho de dialéctica y metafísica. Según la exposición de Aubenque, lo que Aristóteles desarrolla en el libro $\Gamma$ de la Metafisica a propósito de la ciencia del ser en tanto que ser, es lo mismo que lo que le atribuye más brevemente a la dialéctica en el libro I de los Tópicos: superar la pluralidad de las ciencias particulares mediante un discurso más abierto que pueda comunicarlas, y establecer mediante procedimientos dialécticos los principios comunes a todas ellas, como es el caso del principio de no contradicción (PNC). A juicio de Aubenque, en la medida en que el establecimiento del PNC no se lleva a cabo mediante procedimientos apodícticos, sino mediante el procedimiento dialéctico de la refutación (élenchos), el PNC, que constituye el fundamento de toda demostración ulterior, no podría ser realmente demostrado. Tal como ya había hecho en Le problème de l'être..., Aubenque se pregunta de nuevo: «¿Diremos que la ciencia del ser en tanto que ser se confunde con la dialéctica?», para responder a continuación: «No lo creemos. (...). Pero podría ocurrir que hubiera coincidencia de hecho [el subrayado es mío] en el caso de que la filosofía no llegara a constituirse como ciencia y per-

10 Se trata de las colecciones de artículos: P. Aubenque, Problemes aristotèliciennes, París, 2009; E. Berti, Dialectique, physique et métaphysique. Études sur Aristote, Lovaina, 2008; y C. Rossitto, Studi sulla dialettica in Aristotele, Nápoles, 2000. 
maneciera en el plano de la búsqueda y la tentativa. (...). Si la búsqueda y la tentativa son el asunto de la dialéctica, entonces la ciencia del ser en tanto que ser es dialéctica, en la medida en que ella, por razones que no son el signo de un fracaso, sino que corresponden a su misma esencia, no puede llegar a constituirse como ciencia» (pp. 27-29). En efecto, en la medida en que toda proposición científica cumple las reglas de dependencia (según la cual toda proposición proviene de axiomas) y de univocidad (según la cual toda proposición pertenece a un género determinado), no cabría hablar científicamente ni de los primeros principios ni de la totalidad, material que constituye, precisamente, el objeto de la dialéctica y de la ciencia del ser en tanto que ser. En el ámbito del conocimiento de los primeros principios y de la totalidad no cabría por consiguiente más posibilidad que «la discusión razonable» (p. 30). Para expresarlo de otro modo, según la interpretación de Aubenque, dialéctica y metafísica se identifican en su limitación, es decir, en la imposibilidad de ambas por llegar al establecimiento de verdades mediante demostración. La tesis defendida por Berti en «La dialettica in Aristotele» constituye en cierto modo el contrapunto de la tesis de Aubenque. Al igual que el erudito francés, Berti identifica dialéctica y filosofía en Aristóteles; pero mientras que Aubenque las identifica en su limitación, Berti las identifica en su poder demostrativo. Berti rechaza el modo habitual en que la dialéctica aparece confrontada con la ciencia; también la idea de que, frente a la verdad que puede procurar la ciencia, la dialéctica simplemente sea capaz de ofrecer opinión; y finalmente, la idea de que, en el mejor de los casos, la dialéctica no sea sino una introducción a la ciencia. Berti recuerda que es el propio Aristóteles quien señala, entre los usos de la dialéctica, la distinción de lo verdadero de lo falso mediante el desarrollo de las consecuencias opuestas ante una misma dificultad ${ }^{11}$. La dialéctica constituye un modo legítimo y eficaz de establecer la verdad y la falsedad, de construir un saber positivo coherente con las exigencias que debe satisfacer el conocimiento filosófico, por lo que la dialéctica entraría de lleno en el ámbito del conocimiento. Al igual que Aubenque, pero a fin de llegar a la conclusión contraria, Berti esgrime la demostración dialéctica del PNC para ilustrar que «tal argumentación dialéctica da lugar a un verdadero saber» (p. 74). Una similar valoración de la dialéctica aristotélica defienden Sichirollo (1973), Irwin (1976-1977), Leszl (1975) y Barnes (1976-77), autores para quienes la dialéctica constituye, en su aspecto

11 Así lo afirma el Estagirita en Top. I 2, 101a35-36: «[la dialéctica] es útil (...) porque pudiendo desarrollar una dificultad en ambos sentidos, discerniremos más fácilmente lo verdadero y lo falso en cada cosa». 
crítico o peirástico, no sólo un estadio preliminar del desarrollo de la ciencia, sino el verdadero método a través del cual se llega a la verdad, es decir, a la constitución positiva y constructiva de la ciencia ${ }^{12}$. A juicio de todos los autores citados, las ciencias particulares no sólo se sirven de numerosos procedimientos dialécticos, de tal modo que cabe afirmar que la dialéctica participa en la construcción positiva del saber, sino que en algunos ámbitos, como es el caso de la metafísica o de la ética, la dialéctica constituiría el único procedimiento posible. En lo que respecta a la importancia atribuida a la dialéctica en el proceso de constitución de la ciencia del ser en tanto que ser, puede observarse que la opinión de estos autores no difiere notablemente de la de Aubenque; la diferencia entre la posición de aquéllos y la del erudito francés radica en la distinta valoración que aquéllos y éste conceden a la calidad del conocimiento que pueda establecerse mediante los procedimientos dialécticos, pero no a la importancia atribuida a la dialéctica en la constitución de la filosofía primera y de las ciencias particulares. Una valoración diferente ha sido defendida por Lugarini (1961) y, posteriormente, por Couloubaritsis (1978-79). Ya ha sido comentada la trascendencia que, en varios sentidos, tuvo la publicación del trabajo de Lugarini «Dialettica e filosofia in Aristotele». En ese primer trabajo, Lugarini afirmaba que "la dialéctica (...) resulta de hecho [el subrayado es mío] el método mismo de la filosofía» (p. 67). El erudito italiano entendía la dialéctica aristotélica principalmente como diaporética y se servía del esquema básico aporein-diaporein-euporein para describir la estructura de la Metafísica y subrayar así la importancia de la dialéctica en su constitución. Sin embargo, en su posterior trabajo de 1961, Lugarini renuncia a identificar dialéctica y filosofía, y rebaja el papel de la dialéctica en la constitución de la filosofía primera. Según su nueva interpretación, Lugarini limita la implicación de la dialéctica a los momentos aporético y diaporético, pero la excluye del momento euporético, que correspondería al momento científico, positivo y no dialéctico de la solución: «La identificación de la dialéctica, tal como es concebida por Aristóteles, con el método de la filosofía es sostenida también en mi trabajo Dialettica e filosofia in Aristotele. La ulterior profundización en la cuestión, (...), me ha convencido posteriormente de la necesidad de circunscribir un poco la tesis propuesta en aquel trabajo. Para Aristóteles, en efecto, la dialéctica (entendida siempre como método discursivo) entra sólo en los dos primeros momen-

12 Sichirollo, 1973, op. cit., Irwin, 1976-1977, op. cit. y Leszl, 1975, op. cit. analizan casos tomados de la ciencia del ser en tanto que ser, mientras que Barnes, 1976-77, op. cit. se centra en casos tomados de la ética y de la física aristotélicas. 
tos del filosofar: en el aporético y en el diaporético. Por motivo de su desarrollo dialógico ella permanece por el contrario excluida de la fase más estrechamente epistémica del filosofar y en general de la búsqueda científica que es el momento euporético en el que se trata de formular un «logos» explicativo de la cosa misma» (pp. 167-8, n. 30). Así pues, aun siendo fundamental el papel jugado por la dialéctica en la constitución de la filosofía primera, su presencia no es ni suficiente ni exclusiva, de modo que, junto a los procedimientos dialécticos de las ciencias, habría que considerar también la presencia de una fase euporética, no dialéctica, de argumentación positiva en la que Aristóteles establecería su propio pensamiento. A una conclusión similar llega Couloubaritsis (1978-79), quien reconoce explícitamente su deuda con Lugarini.

Matizadas pero importantes diferencias se dan, por consiguiente, en el modo de valorar la presencia de la dialéctica en la constitución de la filosofía primera. ¿Existe alguna declaración en la que el Estagirita se pronuncie claramente a este respecto? Entiendo que sí: en primer lugar, debe valorarse el hecho de que en numerosas ocasiones Aristóteles distingue dialéctica y filosofía de un modo explícito $^{13}$. Pero además, la opinión del Estagirita sobre el poder y los límites de la dialéctica en la conformación de la filosofía primera está expresada de modo inequívoco en dos pasajes, uno perteneciente a los Tópicos, y otro perteneciente al libro Beta de la Metafísica, textos, por otra parte, considerados unánimemente «dialécticos». En el libro primero de los Tópicos, Aristóteles enumera los usos de la dialéctica del siguiente modo:

«[la utilidad de la dialéctica] lo es para tres cosas: para ejercitarse, para las conversaciones y para los conocimientos de filosofía. (...); para los conocimientos de filosofía, porque, a) pudiendo desarrollar una dificultad en ambos sentidos discerniremos más fácilmente lo verdadero y lo falso en cada cosa. Pero es que b) además es útil para las cuestiones primeras propias de cada conocimiento. En efecto, a partir de lo exclusivo de los principios internos del conocimiento en cuestión, es imposible decir nada sobre ellos mismos, puesto que los principios son primeros con respecto a todas las cosas, y por ello, es necesario discurrir en torno a ellos a través de las cosas plausibles concer-

13 Cf. Tóp. I 14, 105b30-31 y VIII 1, 155b7-12 y Met. Г, 1004b17-27. La distinción entre dialéctica (y retórica) y ciencias, en $R h$. I, 1355b8, 25-34; 1358a10-35; 1359b8-10 y APr. I, 77a2635 . 
nientes a cada uno de ellos. Ahora bien, esto es propio y exclusivo de la dialéctica: en efecto, al ser adecuada para examinar "cualquier cosa", abre camino a los principios de todas las ciencias (I 2, 101a25-b4)».

Es indiscutible que el Estagirita atribuye a la dialéctica un valor filosófico de primera magnitud; en primer lugar, el texto hace referencia al método diaporético, al que le atribuye la capacidad de favorecer el acceso a la verdad y a la falsedad sobre cuestiones de pertinencia filosófica; en segundo lugar, también hace referencia a los primeros principios, cuyo establecimiento pertenece a la dialéctica, al entender que los principios, en tanto que principios, no pueden ser establecidos mediante procedimientos apodícticos, sino mediante procedimientos indirectos ajenos a la silogística. A lo largo de la Metafísica, Aristóteles hace uso, efectivamente, de los procedimientos dialécticos señalados en este fragmento, tales como el desarrollo diaporético de B 2-6 o la demostración refutativa del PNC. Sin embargo, es el propio Aristóteles quien establece también los límites de tales procedimientos en la constitución del conocimiento, y así lo manifiesta claramente en la introducción del libro B de la Metafisica ${ }^{14}$. En efecto, al comienzo del libro de las aporías, Aristóteles describe las fases del método diaporético del siguiente modo:

«Es necesario, con vistas a la ciencia que estamos buscando, que nosotros nos dirijamos primeramente a esas cuestiones sobre las que en primer lugar deben plantearse aporías (aporêsai); y son tales cuantas cuestiones acerca de las cuales algunos han sostenido opiniones distintas, y también, aparte de esas, si alguna otra resulta que ha sido pasada por alto. Para aquellos que desean encontrar una salida adecuada a las aporías (euporêsai), les es útil recorrerlas minuciosamente (diaporêsai), pues la ulterior salida adecuada no consiste sino en la liberación de lo que previamente era aporético (B 1, 995a25-30)».

En este clarificador texto del libro B, Aristóteles describe las tres fases que cabe distinguir en el proceso diaporético: 1) el establecimiento de las aporías o dificultades, tanto las heredadas de la tradición como aquellas que hayan podi-

14 Sobre los libros aporéticos de la Metafísica y su importancia en la constitución del saber se han publicado recientemente varios trabajos monográficos: A. Madigan, Metaphysics: Books B \& K 1-2, Oxford, 1999; A. Motte \& Chr. Rutten (eds.), Aporia dans la philosophie grecque des origines à Aristote, Louvain-La-Neuve, 2001; V. Celluprica (ed.), Il libro B della Metafisica di Aristotele, Roma, 2003; y J. Aguirre, La aporía en Aristóteles. Libros B y K 1-2 de la Metafísica, Madrid, Dykinson, 2007. 
do pasarse por alto en el pasado; 2) el recorrido minucioso de las aporías, fase que consiste en la deducción a partir de premisas dialécticas (éndoxa) de las dificultades derivadas de cada una de las tesis contrarias que conforman cada aporía; y 3) el desarrollo de la solución positiva para cada una de las cuestiones aporéticas planteadas. Estas tres fases pueden ser descritas, respectivamente, como aporética, diaporética y euporética. De la lectura del texto se desprende que la fase euporética posee una naturaleza propia, distinta y no derivada directamente de la fase diaporética, por mucho que ésta represente un momento útil (proúrgou, a28) en el proceso global de búsqueda de la solución final. Dicho de otro modo: tanto de lo expresado por Aristóteles en el citado fragmento como de su posterior modo de enfrentarse a la búsqueda de soluciones para las aporías a lo largo de los libros centrales de la Metafísica, cabe afirmar con seguridad que la fase euporética va más allá de lo establecido por los procedimientos propiamente dialécticos de las fases aporética y diaporética del proceso. En la Metafísica, cuya estructura general puede ser descrita mediante el recurso a las tres fases arriba descritas, encontramos, efectivamente, numerosos casos de aporías cuya solución se encuentra en un plano distinto al del desarrollo diaporético expuesto a lo largo de B 2-6 $6^{15}$. En los próximos apartados se ilustrará todo ello mediante el análisis de la solución desplegada por Aristóteles a dos aporías de Beta, la undécima ( $¿$ “Lo ente» $y$ «lo uno» son esencias de las cosas o no?) y la decimoquinta ( $: L o s$ principios son universales o singulares?), muy cercanas en cuanto al tema pero muy distintas en lo que concierne al resultado de su búsqueda.

\section{La naturaleza de lo ente y lo uno}

La aporía undécima plantea si lo ente y lo uno son esencias de todas las cosas y realidades en sí, o más bien son meros atributos de otras substancias ${ }^{16}$. La Tesis

15 Son diversos los modos en que a lo largo de la Metafisica Aristóteles aborda la solución de las aporías planteadas en B: en unos casos, efectivamente, la solución se identifica con una de las dos tesis contrarias que conforman la aporía; en otros casos, sin embargo, la solución viene dada por la reformulación del problema y por la superación de las dos tesis contrarias; en otros casos, finalmente, Aristóteles no desarrolla una solución definitiva.

16 Sobre la undécima aporía, puede consultarse E. Berti, «Le Probléme de la substantialité de l'être et de l'un dans la Métaphysique", en Aubenque (ed.) Études sur la Métaphysique d'Aristote, Actes du VI Symposium Platonicum, París, Vrin, 1979, pp. 89-129 y "L'essere e l'Uno in Metaph. B», en Celluprica, 2007, op. cit., pp. 103-126; L. Couloubaritsis, «L'Étre et l'un chez Aristote (I) », Revue 
de la aporía plantea que si lo ente y lo uno no son substancias, entonces: a) no lo será ningún otro universal, pues lo ente y lo uno son los universales en grado sumo (B 4, 1001a19-22); b) si lo uno en sí y lo ente en sí no existen aparte de los particulares, entonces no habrá nada universal (1001a22-24); c) si lo uno no es substancia, tampoco lo será el número, pues éste se compone de unidades y uno y unidad es lo mismo (1001a24-27). La Antítesis de la aporía plantea que si lo ente y lo uno son substancias, entonces: a) necesariamente su esencia será «ser uno» $\mathrm{y}$ «ser ente», pues ninguna otra cosa se predica universalmente, sino estas mismas (1001a27-29); b) de acuerdo con el razonamiento de Parménides, no podrá existir nada fuera de lo ente, dado que su esencia consistirá en «ser ente»; y de la misma manera, fuera de lo uno no podrá haber nada que sea uno (1001a29-b1); c) de acuerdo con el razonamiento de Zenón, si lo uno mismo es indivisible, nada será, pues de lo indivisible no puede surgir la magnitud (1001b716); d) en todo caso, no se sabe por qué razón lo generado es unas veces número y otras magnitud (1001b17-25).

Las premisas dialécticas (éndoxa) de las que parte el desarrollo diaporético de la aporía undécima son las siguientes: 1) Ente y uno son substancias de las cosas (1001a10-11; atribuido a Platón y los Pitagóricos. Aristóteles no lo acepta); 2) Ente y uno son accidentes de un sujeto (1001a14-19; atribuido a Empédocles y a los filósofos de la naturaleza jonios; Aristóteles no lo acepta); 3) Existen los universales como substancia (1001a19-21; Aristóteles no lo acepta); 4) Ente y uno son los predicados más universales (1001a21-22; Aristóteles lo acepta); 5) Los números tienen existencia separada (1001a25-26; Aristóteles no lo acepta); 6) Un número es un conjunto de unidades (1001a26; Aristóteles lo acepta parcialmente); 7) Toda realidad es una unidad o una pluralidad compuesta de unidades (1001b6-7; Aristóteles no lo acepta); 8) Lo que es indivisible no es (1001b7-8; atribuido a Zenón. Aristóteles no lo acepta); 9) Cada realidad es una magnitud corpórea (1001b10-11; atribuido a Zenón. Aristóteles no lo acepta); 10) El número procede del uno y de algo más (1001b20. Aristóteles no lo acepta); 11) El número y las magnitudes proceden del uno y de algo más (1001b22; Aristóteles no lo acepta); 12) No es posible que las magnitudes procedan del uno y del número

de philosophie ancienne, I, 1983, pp. 49-98 y "L'Être et l'un chez Aristote (II)», Revue de philosophie ancienne, I, 1983, pp.143-195; J. Cleary, Aristotle and Mathematics: Aporetic Method in Cosmology and Metaphysics, Leiden, E. J. Brill, 1995, pp. 213-25; Madigan, 1999, op. cit., pp. 107-18 y Aguirre, 2007, op. cit., pp. 262-73. 
(1001b24-25. Aristóteles lo acepta). Por otro lado, el desarrollo de la aporía resulta complejo debido a los numerosos significados y usos atribuidos por Aristóteles a ambas nociones. En función de que las nociones de lo ente y lo uno aparezcan en un contexto filosófico pitagórico, platónico, eléata o naturalista, podrán ser identificados con: esencias de las cosas (1001a5-6), realidades en sí en el sentido platónico o, por el contrario, atributos de otra realidad como substrato (1001a6-8; 1001a10-11; 1001a27-28), principio unificador (1001a14), arché y stoicheîon en el sentido dado por los primeros filósofos de la naturaleza (1001a12-19), substancias (1001a20-21), realidades únicas en sentido parmenídeo (1001a29-32), principios de los números (1001a24-27) y principios de las magnitudes (1001b1617). Aristóteles niega la mayor parte de las premisas dialécticas utilizadas en el desarrollo diaporético de la aporía undécima, y también todos y cada uno de los significados atribuidos históricamente a lo ente y lo uno. En este sentido, el desarrollo diaporético constituye una procedimiento fundamental que consiste en aclarar o limpiar el camino de la investigación; pero sin embargo, el desarrollo diaporético, tal como es presentado por Aristóteles en B 2-6, es ajeno a la fase euporética o de construcción positiva del saber. En efecto, el proceso de búsqueda de la solución a la aporía undécima posee un nivel de complejidad que desborda la elaboración diaporética llevada a cabo en el libro B. Para ver más claramente en qué consiste este complejo proceso, nos centraremos fundamentalmente en la investigación lo «lo ente» y dejaremos en gran medida de lado la investigación sobre «lo uno».

En primer lugar, en el capítulo primero del libro Z Aristóteles replantea la cuestión aporética en torno a lo ente al establecer que la pregunta por lo ente (tò ón) se remite a la pregunta por la substancia (he ousía):

«... la cuestión que se está indagando desde antiguo y ahora y siempre, y que siempre resulta aporética, qué es lo ente, viene a identificarse con ésta: ¿qué es la substancia? (Z 1, 1028b2-3)»

A fin de justificar la identificación entre lo ente y la substancia, Aristóteles parte de una población de substancias cuya existencia no pone en duda: las substancias sensibles. Situado en este contexto, el filósofo asume dos ideas que actúan como premisas: 1) «lo ente» se dice de muchos $\operatorname{modos}^{17}$; y 2) ser substan-

17 Cf. Z 1, 1028a10: tò òn légetai pollachôs. Cf. también A 3, $992 b 18$ ss.; Г 2, 1003a33; 1003b5; $\Delta$ 7; 10, 1018a35; 11, $1019 \mathrm{a} 4$ ss.; E 2, 1026a33-b2; 4, 1028a5 ss.; K 3, $1060 \mathrm{~b} 32$ ss.; 1061b11; 1064b15; M 2, 1077b17; N 2, 1089a7; 1089a16. 
cia es el modo primero entre todos los modos de $\operatorname{ser}^{18}$. De la confirmación de estas dos premisas depende la justificación de la investigación de la substancia como modo de acceso al conocimiento de lo ente.

¿Qué significa que «lo ente» se dice de muchos modos? En el contexto de la ontología aristotélica ente y ser expresan originalmente una pluralidad de significados irreductibles entre sí pero referidos en última instancia a un solo principio, la substancia. En Met. $\Delta 7$ Aristóteles expone los distintos modos en que puede afirmarse que algo es: según la conocida clasificación del filósofo, que es puede decirse accidentalmente (katà sumbebekós), por si (kath'autó), verdadero (alethés) y falso (pseudos), y en potencia (dynámei) y en acto (entelecheiai) ${ }^{19}$.

Por accidental Aristóteles entiende «aquello que se da en algo, y su enunciación es verdadera, pero no necesariamente ni la mayoría de las veces $(\Delta 30$, 1025a14-15)», tal que el hombre es músico, pero también «las propiedades que pertenecen a la cosa por sí misma sin formar parte de su substancia $(\Delta 30$, 1025a31)", tal que pertenece al triángulo tener dos rectos. Aristóteles distingue también ser como verdadero, tal que Sócrates es músico y no ser como falso, tal que la diagonal no es conmensurable con el lado. Se trata de un sentido que debe ser entendido como una afección de la mente del sujeto pensante. Tanto el modo de ser accidental como el ser en tanto que verdadero y falso son considerados por Aristóteles modos de ser de segundo orden, pues «la causa del uno es indeterminada y la del otro es cierta afección del pensamiento (Z 4, 1027b34)», e incluso manifestará que «el accidente parece estar próximo a lo que no es (E 2, 1026b20)». En cuanto al modo de ser en potencia y en acto, distinción de enorme importancia dentro de la ontología aristotélica, hay que destacar el hecho de que tampoco constituye un significado unívoco, sino que adquiere sus distintos significados en función de los otros modos de ser. Junto a estos tres modos de ser, Aristóteles destaca un modo de ser primero de ser, que es el ser por sí. A juicio del filósofo, el ser por sí es el modo de ser que deberá ser analizado en vistas al estudio de la relación existente entre ser y substancia. En el grupo de significa-

${ }^{18}$ Cf. Z 1, 1028a32. Cf. también Г 2, 1003b16-19.

19 Este mismo esquema se retoma posteriormente en Z 2, 1026a33-b2, I 10, 1051a34-b1 y N 2, 1089a26-28. Es importante retener que en la clasificación realizada por Aristóteles los modos de ser no se reducen a los accidentes y al ser por sí, ni el ser por sí se reduce a la substancia; el ser por sí incluye también las figuras de las categorías. 
dos reunido en la expresión lo ente o ser por sí, Aristóteles se ocupa de «todas las cosas significadas por las distintas figuras de la predicación $(\Delta 7,1017 \mathrm{a} 23){ }^{20}$, es decir, de todas las categorías de lo ente, y no sólo de la categoría de substancia. En este sentido, debe tenerse en cuenta la importante precisión de que las categorías descritas por Aristóteles no hacen referencia a las realizaciones concretas que en cada caso puedan darse en un sujeto determinado y que son expresables en el lenguaje mediante proposiciones de hecho, sino a las figuras que manifiestan modos de ser por sí irreducibles ulteriormente. Esa es la razón por la que todas las categorías del ser - y no sólo la categoría de substancia — son integradas por Aristóteles en el sentido primordial de lo ente. De las varias listas confeccionadas por el filósofo, la más conocida pertenece a las Categorías: substancia (ousía), cantidad (posón), cualidad (poión), relación (prós ti), lugar (poú), tiempo (póte), situación (keisthai), posesión (echein), acción (poiein) y pasión (páschein) ${ }^{21}$.

Pero si se admite la existencia de cuatro modos de ser, e incluso la multiplicidad de significados dentro de cada uno de esos modos - por ejemplo, la multiplicidad irreducible de las figuras de las categorías dentro del ser por sí, o la multiplicidad de sentidos de la potencia y el acto-, ¿cómo puede justificarse la existencia de una ciencia de lo ente en tanto que ente (tò òn e ón), habida cuenta de que lo ente constituye una multiplicidad y no un género? La solución de Aris-

20 En lo que respecta a esta afirmación de Aristóteles, es clarificador el comentario de T. Calvo Martínez, Aristóteles. Metafisica, Madrid, Gredos, 1988, pp. 224, nota 31: «A primera vista (...) cabría esperar que Aristóteles, tras ocuparse de lo ente accidentalmente, se refiera ahora exclusivamente a la ousía, a la substancia, como aquello que es por sí. Sin embargo, Aristóteles afirma que son por sí todas las cosas significadas por las categorías y, por lo tanto, también las significaciones correspondientes a las categorías de los accidentes. (...). Esta fórmula [por si] no se refiere a la relación entre sujeto y predicado (...), sino a la relación entre los distintos predicados posibles y el ser: las determinaciones correspondientes a cualquier categoría son por sí, es decir, en cuanto tales, y de modo inmediato expresan distintos modos de ser, sea cual sea la relación que, a su vez, guarden con el sujeto.» Según esta interpretación, las categorías no sólo admiten una interpretación lingüística, lógica y semántica, sino también ontológica, en la medida que manifiestan modos de ser por sí no reducibles posteriormente. Una breve pero precisa interpretación de la cuestión se encuentra en J. Kung, "Aristotle on "being is said in many ways" ", History of Philosophy Quaterly, 3, 1986, pp. 3-18.

${ }^{21}$ Cf. Cat. IV. Una lista de 10 categorías aparece también en Top. IX 103b23, con la diferencia de que la categoría de ousía es sustituida por la de tí esti. Y otra lista más, conteniendo sólo las 8 primeras categorías, en Phys. V 225b5-9. Para un análisis detallado de las categorías, puede consultarse F. A. Trendelenburg, La dottrina delle categorie in Aristotele, Milán, Vita e Pensiero, 1994, (1. ${ }^{a}$ ed. alemana, 1846). 
tóteles a esta cuestión viene dada mediante la referencia de todos los modos de ser a un único principio:

«La expresión algo que es se dice en muchos sentidos, pero en relación con una sola cosa y una sola naturaleza y no por mera homonimia $(\Gamma 2$, 1003a34-35)».

Todo aquello que llamamos ser o ente recibe esa denominación por referencia a cierta naturaleza por analogía, y no simplemente por homonimia o equivocamente; la naturaleza a la que Aristóteles se refiere es la substancia:

«... algo que es se dice en muchos sentidos, pero en todos los casos en relación con un único principio: de unas cosas <se dice que son> por ser substancias, de otras por ser afecciones de la substancia, de otras por ser un proceso hacia la substancia, o bien corrupciones o privaciones o cualidades o agentes productivos o agentes generadores, ya de la substancia ya de aquellas cosas que se dicen en relación con la substancia, o bien por ser negaciones ya de alguna de estas cosas ya de la substancia. Y de ahí que, incluso de lo que no es, digamos que es algo que no es $(\Gamma 2,1003 \mathrm{~b} 6-10)$ ».

La referencia última de todos los modos de ser a la substancia justifica la afirmación de la primacía de la substancia sobre el resto de los modos de lo ente y, consecuentemente, la investigación de la substancia como vía de acceso a la investigación del ser. Todo ello, a su vez, justifica la posibilidad de una ciencia de lo ente en tanto que ente.

Así pues, la substancia es el modo primero de ser. ¿Cuáles son los criterios por los que Aristóteles atribuye la primacía del ser a la substancia? A lo largo de los libros centrales, el Estagirita se esfuerza en dar respuesta a la cuestión. El primero de los criterios establecidos por Aristóteles para establecer la primacía de la substancia sobre el resto de modos de ser modos lo constituye el criterio de dependencia; en el citado fragmento de $\Gamma 2$ aparecen expuestos los modos en que puede ser entendida la dependencia respecto a la substancia. Aristóteles resume en $\mathrm{Z} 3$ su postura mediante la siguiente afirmación:

"Quede esquemáticamente dicho qué es la substancia: aquello que no "se dice" de un sujeto, pero de ello "se dicen" las demás cosas. (Z 3, 1029a8)»".

${ }^{22}$ Cf. también Cat. 5, 2a11. 
Substancia es, por consiguiente, aquello que no es afirmado de un sujeto ni se halla en un sujeto, sino que todo se dice en referencia a ella y existe en torno a ella. Todos los modos de ser y todas las categorías son y se dicen en relación a la substancia. Ahondando en el tema de la primacía de la substancia y de la dependencia de todas las otras formas de ser, Aristóteles investiga aquellos sentidos en que puede afirmarse que la substancia es prioritaria o primera, llegando a la siguiente conclusión:

«... primero se dice en muchos sentidos. Pues bien, en todos ellos es primera la substancia: en cuanto a la definición, en cuanto al conocimiento y en cuanto al tiempo. En efecto, ninguna de las otras cosas que se predican es capaz de existencia separada, sino solamente ella. Y también es ella primera en cuanto a la noción (ya que en la noción de cada una de las demás está incluida necesariamente la de la substancia); y, en fin, pensamos que conocemos cada cosa, sobre todo, cuando sabemos qué es el hombre o el fuego, más que si sabemos la cualidad, la cantidad o el dónde. ( $\mathrm{Z} 1$, 1028a31-b1)».

La prioridad de la substancia en tanto que realidad capaz de existencia separada constituye el correlato ontológico de la prioridad de la substancia en el decirse, pues el decirse todo en relación a la substancia tiene su origen en la existencia separada de la misma, en su independencia con respecto a cualquier otro modo de ser no substancial. Mientras que las substancias son separadas o independientes, las no substancias dependen de aquéllas; y mientras que las no substancias existen necesariamente en substancias como sujetos, éstas no existen sino en sí mismas. Esta diferencia indica una asimetría ontológica fundamental entre la substancia y el resto de modos de ser. En este sentido, puede afirmarse también que las substancias constituyen realidades básicas desde el punto de vista ontológico, y que esta prioridad de la substancia conlleva la prioridad en el tiem$\mathrm{po}^{23}$. Ni las propiedades ni las nociones universales poseen la independencia onto-

${ }^{23}$ A este respecto, es clarificador el comentario de W. D. Ross, Aristotle’s Metaphysics, texto y comentario inglés en dos tomos, Oxford, Clarendon Press, 1997 (1. ${ }^{a}$ ed. 1924), pp. 160-1: «It seems best to suppose with Alexander that next words (ll. $33 \mathrm{f}$ ) are meant to explain chronoi. That which can exist without other things while they cannot exist without it may naturally be said to exist before other thing. (...). Alexander is probably right in supposing that 1l. 34-36 refer to logoi and 1l. 36-b2 to gnóseì. 
lógica necesaria para poder ser considerados substancias. Por otro lado, la prioridad de la substancia en cuanto a la definición se explica por el hecho de que la definición de cualquier ser no substancial incluye la definición de una substancia. Por el contrario, cualquier substancia puede ser definida sin hacer mención a una realidad no substancial. Para entender la relación entre definición y substancia hay que recordar que la pregunta por la substancia es respondida recurriendo, precisamente, a la definición, de modo que puede afirmarse que la definición constituye el predicado que indica la substancia. La definición, en efecto, no es un enunciado simplemente lingüístico, sino ontológico, indicativo de la causa del ser. Finalmente, la prioridad de la substancia respecto al conocimiento es una consecuencia de la prioridad en la definición: es más importante conocer lo que una cosa es que conocer cualquiera de sus propiedades. A su vez, conocemos una cualidad o una cantidad en sentido completo cuando conocemos lo que una u otra son; pero ambas las conocemos en su pleno sentido por medio de la definición, que a su vez conlleva el conocimiento de la definición de la substancia.

Parece claro que los tres modos de prioridad de la substancia están interrelacionados: la prioridad en cuanto al conocimiento es una consecuencia de la prioridad en cuanto a la definición, y ésta, a su vez, es una consecuencia del carácter básico (y anterior) de la substancia en el orden de la existencia. ¿Justifica la prioridad de la substancia su estudio en vistas a la investigación de lo ente? El mismo Aristóteles responderá claramente a esta cuestión:

«...en todos los casos la ciencia se ocupa fundamentalmente de lo primero, es decir, de aquello de que las demás cosas dependen y en virtud de lo cual reciben la denominación. Por tanto, si esto es la substancia, el filósofo deberá hallarse en posesión de los principios y causas de las substancias. ( $\Gamma 2$, 1003b16-19)»

Así pues, según Aristóteles los principios y las causas de las substancias son, a su vez, principios y causas del ser de las no substancias; y por consiguiente, al investigar los principios y el ser de la substancia se están investigando también los principios y el ser de las no substancias. Respondiendo a la cuestión planteada al comienzo del parágrafo, la cuestión central de la ciencia de lo ente en tanto que ente puede transformarse en la siguiente cuestión: ¿Cuáles son los principios y causas de la substancia? 
Una vez admitido que el modo privilegiado de ser corresponde a la substancia, Aristóteles dirige la investigación al descubrimiento de la realidad que pueda ostentar tal título. La cuestión es tratada por el Estagirita principalmente en los libros $Z$ y E. Aunque en ningún lugar de su obra recoja sistemáticamente las características que debe reunir la substancia para poder ser considerada como tal, y a pesar de que los candidatos a substancia en sentido primero son numerosos, Aristóteles llega finalmente a la firme conclusión de que la substancia es la forma, identificada con la esencia expresada en el enunciado de la definición. El principal texto sobre los posibles candidatos a substancia lo encontramos en $\mathrm{Z} 3$ :

«La substancia se dice, si no en más sentidos, al menos fundamentalmente en cuatro: (...) la esencia (tò tí en einai), el universal (tò kathólou), el género (tò génos) y (...) el sujeto (tò hypokeimenon). (Z 3, 1028b33-36)»

Unas líneas más adelante añade:

«Parece que substancia es, en grado sumo, el sujeto primero. Y se dice que es tal, en un sentido, la materia (he hýle), en otro sentido la forma (tò eidos), y en un tercer sentido el compuesto (tò sýnolon) de ambas. (Z 3, 1029a2-4)»

Sin salir del ámbito de investigación de las substancias sensibles, Aristóteles propone cuatro alternativas, si bien se decanta en un principio por el sujeto primero como modo de ser identificado con la substancia. Esta elección es coherente con lo afirmado por el filósofo en distintos lugares de su obra: la característica primera de la substancia consiste en no predicarse de ningún sujeto sino predicarse todo lo demás de ella ${ }^{24}$. Sin embargo, tal como el propio Estagirita admite, bajo este criterio son tres las realidades que podrían responder al nombre de substancia: la materia, la forma y el compuesto de ambas. Si se analizan las características que Aristóteles atribuye a la substancia, entonces puede comprobarse que la materia sólo puede ser considerada substancia en un sentido derivado y secundario. Así, en $\Delta 8$, puede leerse que, además de a) aquello que no se predica de ningún otro sujeto sino que todo se predica de ello, Aristóteles señala como substancia: b) «lo que es causa inmanente del ser de aquellas cosas que no se predican de un sujeto $(\Delta 8,1017 \mathrm{~b} 15-16)$ », c) «las partes inmanentes de tales cosas, si las delimitan y expresan algo determinado $(\Delta 8,1017 \mathrm{~b} 18-19)$ » $\mathrm{y}$

${ }^{24}$ Cf. $\Delta 8,1017 \mathrm{~b} 10-14 ;$ Z 3, 1029a7-8. 
d) «la esencia cuyo enunciado es la definición $(\Delta 8,1017 \mathrm{~b} 23)$ ». E inmediatamente Aristóteles resume:

«(...) la substancia se denomina: de una parte, 1) el sujeto último que ya no se predica de otra cosa; de otra parte, lo que siendo 2) algo determinado (tóde ti) es también capaz de 3) existencia separada (choristón)».

De un modo mucho más extenso, Aristóteles desarrolla a lo largo de Z 3 lo esbozado en $\Delta 8$. Finalmente, a las citadas tres características atribuidas por Aristóteles a la substancia, se añaden posteriormente otras dos: 4) el constituir una uni$d a d^{25}$ más que un agregado informe, y 5) el existir en acto más que en potencia ${ }^{26}$. Si se tienen en cuenta todas las características atribuidas por el Estagirita a la substancia, puede comprobarse que la materia solamente cumple la primera de ellas, pero no las restantes: la materia, efectivamente, es sujeto que no se predica de ninguna otra realidad, pero no existe como realidad separada y determinada, no conforma por sí misma una unidad, ni existe en acto; por el contrario, la materia es potencia indeterminada incapaz de existencia sin la presencia de un principio capaz de actualizarla y darle unidad. Adelantaremos que, dentro de la realidad compuesta sensible, ese principio unificador y actualizador lo constituye la forma, que significa también el tóde ti y el choristón, donde tóde ti significa la determinación formal o esencial más que el individuo empírico o sýnolon, y donde choristón no hace referencia al individuo empírico sino al toi lógoi choristón, es decir, a aquello que es separable mediante el pensamiento, es decir, la forma ${ }^{27}$. Por lo tanto, si Aristóteles no admite la materia como modo primero de ser substancia —es decir, como sujeto último, separable, determinado, constituyente de una uni-

${ }^{25}$ Cf. Z 2 y E 6 passim.

26 Cf. $\Theta 2$ passim.

${ }^{27}$ Cf. E 1, 1042a29 ss. A este respecto, es clarificadora la observación de G. Reale, Aristotele. La Metafisica, Milán, Vita e Pensiero, 1995, pp. 235-6, nota 10: «Si noti che, qui, Arist. esplicitamente riduce il tóde ti all'eidos. Contrariamente a quanto comunemente si retiene, tóde ti non significa affatto l'individuo empirico, il questo qui come qualcuno traduce; l'espressione indica, invece, un carattere che può applicarsi sia all'individuo o al concreto determinato, sia alla forma, e significa, precisamente, la determinatezza essenziale e formale, e, di conseguenza, quindi l'essere un qualcosa di formalmente determinato. Riferito all' individuo, esso significherà qualcosa di determinato, come una materia che ha il suggello della sua forma, dalla quale è pienamente determinata; riferito alla forma, esso significherà un qualcosa di determinato-determinante (...). Per quanto concerne il choristón (separabile) riferito alla forma, è chiaro che si debe intendere soprattutto nel senso di choristón toi lógoi, vale a dire separabile col o per il pensiero (...)». 
dad y en acto- - y si se admite, tal como se mostrará más adelante, que el universal y el género no pueden ser substancias, solamente resta como posible respuesta a la pregunta por la substancia aquello que es designado como esencia y forma. ¿Por qué frente a la tradición presocrática Aristóteles elige la forma más que la materia o el compuesto como substancia en sentido privilegiado? Para responder a esta cuestión no debe perderse de vista, en primer lugar, que el objetivo último de Aristóteles es demostrar la existencia formas puras exentas de materia, y que la discusión sobre las substancias compuestas constituye solamente la introducción a la investigación de las substancias no sensibles ${ }^{28}$. Pero además, la preferencia de la forma pura sobre la materia y el compuesto viene determinada por dos hechos que dejan ver la profunda huella platónica en la ontología aristotélica: en primer lugar, porque la esencia constituye el elemento definible del compuesto; en segundo lugar, porque la forma se identifica con la causa final.

La relación entre definición y esencia viene establecido por Aristóteles en Top. 102a1: «Definición es un enunciado que significa la esencia». Del mismo modo se expresa a lo largo de Met. Z 4, donde afirma: «Así pues, el enunciado de la esencia de cada cosa es aquel enunciado que expresa la cosa misma sin que ella misma esté incluida en él $(\mathrm{Z} 4,1029 b 20-21){ }^{29}$. Y continúa más adelante: "Por consiguiente, hay esencia de todas aquellas cosas cuyo enunciado es definición $(Z 4,1030 \mathrm{a} 6){ }^{30}$. Aristóteles afirmará también que «la definición, en sentido primario y absoluto, así como la esencia, es de las substancias (Z 4, 1030b5)», que inmediatamente identifica con todo aquello «que posee unidad $(Z 4$, 1030b9) $»^{31}$, siendo precisamente la substancia aquello que posee unidad en sentido primario y fundamental. La relación entre definición, substancia y esencia establecida por el autor a lo largo de Z 4 es reafirmada en Z 5, capítulo que concluye con un resumen de las tesis defendidas:

${ }^{28}$ Cf. Z 3, $1029 b 3$ ss. y 11, 1037a11 ss.

29 Con esta afirmación Aristóteles introduce una importante matización sobre lo que en este contexto ha de entenderse por la expresión "por sí» (kath'autó).

30 A este respecto, es preciso el comentario de Calvo Martínez, 1994, op. cit., pp. 289-80, nota 20: «La esencia (tò tí en einai) es, pues, lo expresado en la definición; todo nombre que refiere una substancia (por ejemplo, «hombre») significa la unidad de una esencia que, a su vez, es explicada o des-plegada en la definición".

31 Posteriormente, Aristóteles afirma: «La definición, en efecto, es un enunciado unitario y de la substancia y, por tanto, ha de ser enunciado de algo unitario, puesto que la substancia significa algo que es uno y determinado ( $\mathrm{Z} 12,1037 \mathrm{~b} 25-27)$ ». 
«Así pues, es evidente que la definición es el enunciado de la esencia, y que la esencia pertenece a las substancias, bien exclusivamente, bien en grado sumo, de modo primario y en sentido absoluto (Z 5, 1031a12-14)».

En Z 6, Aristóteles va más allá, afirmando de un modo explícito la identidad entre esencia y substancia:

"Desde luego, la cosa singular no parece ser algo distinto de su substancia, y la substancia se dice que es la esencia de cada cosa singular ( $\mathrm{Z}$ 6, 1031a17-18)».

Si cada cosa es su substancia y la substancia se identifica con la esencia, entonces cada cosa consistirá en su esencia. Tal como se afirma, cada realidad singular y su esencia son una y la misma cosa, por lo que conocer una realidad singular no es sino conocer su esencia, pues "la esencia y la substancia" no solamente se identifican, sino que también su enunciado es el mismo (Z 6, 1031b33-34)». En el caso de las realidades sensibles, por consiguiente, aquello en que consiste el ser de la cosa - la esencia - y la cosa misma se identifican, y ambos vienen expresados por medio de la definición. La importancia de la relación establecida por Aristóteles entre definición, esencia y substancia deriva del hecho de que la definición trata, precisamente, de las causas y principios del ser, por lo que apunta a la estructura ontológica de la cosa y no simplemente a su significado o aspecto lingüístico. A partir de dicha identificación podrá explicarse la posibilidad de la substancia sensible (entendida como sýnolon o compuesto de materia y forma) como algo separable, determinado, constitutivo de una unidad y en acto. La responsabilidad de todo ello recae sobre la esencia, que debe entenderse, por lo tanto, como causa y principio, y que finalmente se identifica con la forma dentro de la composición hilemórfica del compuesto ${ }^{32}$.

En cuanto a la relación entre definición y materia y compuesto, la postura de Aristóteles queda expuesta en el siguiente fragmento de Z 10:

${ }^{32}$ La identificación aristotélica de forma y esencia (y ambas con la causa final) aparece claramente expuesta en Z 17, donde el filósofo establece indistintamente como causa de la unidad de la materia la esencia (1041a28) y la forma (1041b8). Esta identificación aparece en otras ocasiones a lo largo de Z 7 y Z 9 . 
«... de la substancia compuesta hay definición en cierto sentido y en cierto sentido no: en efecto, no la hay si se toma con la materia (ya que es algo indefinido), pero sí que la hay de la substancia primera, por ejemplo la del hombre es el enunciado del alma. Y es que la substancia es la forma inmanente de la cual, juntamente con la materia, resulta la que llamamos substancia compuesta $(Z$ 10, 1037a26-30)».

La unidad de la cosa compuesta viene establecida, pues, por la esencia como objeto de definición, mientras que la materia, por su carácter indeterminado y potencial, no es unidad ni será, por lo tanto, definible.

En cuanto a la identificación aristotélica de la forma con la causa final, tal identificación cabe situarla en el contexto de una física marcadamente teleológica. A lo largo de Phys. II 1, Aristóteles distingue dos modos de entender la naturaleza (y más concretamente, el principio interno de movimiento y reposo) como materia primera y como forma o la especie según la definición ${ }^{33}$, de modo que, tal como asume en el siguiente capítulo, el investigador de la naturaleza debe conocer tanto la una como la otra ${ }^{34}$. Sin embargo, la prioridad de la forma sobre la materia en cuanto a naturaleza queda plenamente establecida por el filósofo mediante tres argumentos: porque la naturaleza es fundamentalmente acto realizado (entelécheia), porque cada substancia nace de otra substancia determinada formalmente, y porque toda generación es un proceso hacia la forma ${ }^{35}$. Los tres argumentos presentados por Aristóteles a favor de la naturaleza entendida como forma más que como materia ponen de manifiesto la íntima relación existente entre forma y fin, en un contexto marcado por el carácter profundamente teleológico de la naturaleza. La naturaleza entendida como fin es ampliamente tratada por Aristóteles en numerosos lugares, preferentemente en sus estudios físicos y biológicos. Así, sin salir de II 2, puede leerse:

«Es, pues, evidente que en las cosas naturales lo necesario es lo que llamamos materia y sus movimientos. El físico ha de establecer ambas causas, pero sobre todo la causa final, ya que ésta es la causa de la materia y no la materia del fin. El fin es aquello para lo cual, y el principio de la definición y del concepto, como en el caso de los productos artificiales (II 9, 200a31-35)».

\footnotetext{
33 Cf. Phys. II 1, 193a28-30.

${ }^{34}$ Cf. Ibídem 2, 193b21-27.

35 Cf. Ibídem 193b7-18.
} 
En su estudio de la naturaleza Aristóteles da prioridad a la causa final, fin o aquello para lo cual, que el filósofo identificará con la causa formal en varios pasajes de su obra. Así, en Phys. II afirma:

«...las causas son cuatro (...) la materia (...) la forma (...) lo que hace mover y el fin. Las tres últimas se reducen en muchos casos a una, pues la esencia y el fin son una misma cosa, y aquello de lo que primeramente proviene el movimiento es específicamente lo mismo que éstas, pues el hombre engendra al hombre (II 7, 198a25-27)».

Y más adelante:

«Y puesto que la naturaleza puede entenderse como materia y como forma, y puesto que esta última es el fin, mientras que todo lo demás está en función del fin, la forma tiene que ser causa como causa final (II 8, 199a31-33) ${ }^{36}$.

La identificación de fin y forma en los seres naturales, estalecida por Aristóteles en la Física y en los trabajos de biología, es afirmada también en la Metafísica:

«...naturaleza son la materia prima (pròte hýle) (...) y también la substancia, es decir, la forma (kaì tò eidos kaì he ousía). Esta es, a su vez, el fin de la generación (tò télos tes genéseos) $(\Delta 4,1015 \mathrm{a} 7-11) \aleph^{37}$.

Si la forma de una realidad se identifica con el ser de dicha realidad expresada en su definición, y el fin o causa final es aquello a lo que una cosa o proceso tiende, ¿cómo identifica Aristóteles ambos conceptos en el caso de los seres naturales? La respuesta a esta cuestión viene establecida por el hecho de que el objetivo o fin de la generación de los seres naturales consiste, precisamente, en la adquisición o actualización de su forma, que en su caso se realiza en la materia. Este esquema teleológico le permite a Aristóteles explicar la generación de los seres naturales, pero también su conducta, así como la explicación de determinados procesos de la naturaleza (por ejemplo, la formación de los órganos de los animales $^{38}$ ) y, de un modo más general, poseer una concepción global de la realidad.

\footnotetext{
36 Cf. también 194a24-29; Part. An., 639b14-21, 641b24 ss.; GC II, 335 b6.

37 Cf. también E 4, 1044a36-37.

38 Cf. Part. An. 645b14-21.
} 
Resumiendo todo lo dicho hasta el momento, podríamos afirmar que la pregunta por lo ente se identifica con la pregunta por la forma de cada substancia compuesta, que cabe entenderla como la esencia de esa cosa expresada en su definición, identificada con el fin, y responsable del ser de dicha substancia, es decir, responsable de que ésta sea una realidad unificada, determinada y actual, y no un mero agregado de materia indeterminado y potencial. Como puede comprobarse, el desarrollo euporético de la aporía undécima conlleva una complejidad que supera en gran medida el desarrollo diaporético de B 4.

\section{La naturaleza particular o universal de la forma substancial}

Veamos ahora el desarrollo de la aporía decimoquinta, estrechamente relacionada con la aporía anterior. La aporía decimoquinta plantea si los principios son universales o particulares. La Tesis de la aporía plantea que, si los principios son universales, entonces: a) no serán substancias, puesto que lo universal no expresa un esto (tóde ti), sino una cualidad (toiónde). Antítesis: si los principios son particulares, entonces: a) no serán cognoscibles, pues la ciencia es de lo universal.

Las premisas dialécticas (éndoxa) de las que parte el desarrollo diaporético de la aporía decimoquinta son las siguientes: 1) Ninguno de los predicados comunes significa un esto (1003a8; Aristóteles lo acepta); 2) La substancia es un esto (1003a9; Aristóteles lo acepta); 3) Los principios particulares no son suficientes para explica el conocimiento (1003a13-14; Aristóteles lo acepta); 4) El conocimiento es de lo universal (1003a14-15; Aristóteles lo acepta); 5) Hay principios que son cognoscibles (1003a15-17; Aristóteles lo acepta). La aporía está estrechamente relacionada con el grupo de aporías 6-939, donde Aristóteles desarrolla una serie de cuestiones relativas a los principios de la substancia desde dos presupuestos: a) las substancias sensibles existen, son reales; b) el verdadero cono-

39 Aporía sexta: ¿¿Son los principios primeros los géneros o los elementos materiales? Aporía séptima: $\mathrm{Si}$ se admite que los principios son los géneros, ¿debe considerarse que son los principios primeros los géneros supremos o los géneros últimos? Aporía octava: ¿Existe algo a parte de los singulares o no? Y si existen las formas separadas, ¿las hay de todos los compuestos concretos o solamente de algunos? Aporía novena: ¿La unidad de los principios es solamente específica o también numérica? 
cimiento es siempre de lo universal. Las dos partes de la aporía pueden ser enunciadas del siguiente modo: si las formas son particulares, entonces no serán definibles ni, por consiguiente, inteligibles. Sócrates, identificado con su forma, no será inteligible por no poder ser definido ni, en consecuencia, conocido. En el otro extremo tenemos que, si las formas son universales, entonces no poseerán existencia independiente, pues ella dependerá de la existencia de los singulares en que se den o de que se prediquen. Tanto uno como otro extremo de la cuestión son inaceptables: la substancia, identificada con la forma, constituye, precisamente, la realidad primera en el orden de la existencia y en el orden del conocimiento. Esta aporía tiene su expresión más compleja en el tratado Z, donde Aristóteles afirma a la vez la imposibilidad de que el universal puede ser substancia $(Z 13)$ y la tesis de que, en sentido estricto, solamente la esencia posee definición (Z 4-11). Al comienzo de Met. Z 13 Aristóteles afirma que "parece imposible que algo dicho universalmente pueda ser substancia.» (Z 13, 1038b6). El filósofo desarrolla a lo largo del capítulo las razones de esa imposibilidad: 1) porque la substancia de algo es peculiar a ello y no común o compartido ${ }^{40}$. Si suponemos que un universal es substancia podría preguntarse de cuál de las cosas a las que pertenece es substancia; por el carácter mismo de la substancia no puede ser que lo sea de todas, pero tampoco de una sola de ellas, pues las cosas cuya substancia (esencia) es una son ellas también una y la misma. El carácter común o compartido del universal implica, pues, su imposibilidad para ser esencia (1038b8-15); 2) porque la substancia es un sujeto y no un predicado de un sujeto ${ }^{41}$. La substancia es lo que no se predica de un sujeto, mientras que el universal siempre se predica de más de uno. Este argumento parte de la idea desarrollada al principio del libro $Z$ según la cual las substancias son realidades básicas desde el punto de vista ontológico. El universal, por definición, no es una realidad básica, pues siempre es predicado de algún sujeto, es decir, siempre «existe» en algún sujeto y nunca de modo independiente (1038b15-16); 3) y en el caso de que se argumente que el universal, aun no siendo substancia como lo es la esencia, puede, sin embargo, estar contenido en ella del modo en que, por ejemplo, «animal» está contenido en el hombre y en el caballo, entonces podrá objetarse que a) el universal será esencia de algo («animal» lo será del animal), con lo cual volverán a surgir las dificultades correspondientes al primer argumento; b) si los universales no son substancias sino cualidades o afecciones, resultará absur-

\footnotetext{
40 Cf. Met. Z 13, 1038b6-9.

${ }^{41}$ Cf. Ibídem b15-16.
} 
do afirmar que forman parte de la esencia, pues resultará que las afecciones son anteriores a la substancia; c) puesto que «animal» se da en Sócrates, entonces será la esencia de dos cosas, de "hombre» y de Sócrates; d) la unidad propia de la substancia excluye que pueda estar compuesta de varias substancias actualizadas, es decir, en acto (1038b16-39a14).

La exposición de Z 13 ha llevado a numerosos especialistas a defender la tesis de que la forma o esencia es particular para cada substancia individual ${ }^{42}$. El problema reside en que el contenido de Z 13, muy explícito respecto a la no universalidad de las substancias, es claramente incongruente con lo afirmado por Aristóteles en el resto del tratado Z. El aspecto principal del problema lo constituye la consideración epistemológica de que la definición y el conocimiento son universales: el filósofo ha establecido que la esencia, identificada con la substancia (Z 6), es expresada o explicada en el enunciado de su definición ( $Z$ 4), que, a su vez, constituye siempre un enunciado de lo universal y de la forma, pues del compuesto particular no existe definición $(Z 10,11,15)$. De todo ello parece poder afirmarse, por consiguiente, que la esencia es universal. Asimismo, el filósofo ha establecido que el conocimiento de una determinada realidad se identifica con el conocimiento de su esencia, y que el verdadero conocimiento lo es de lo universal, de donde parece deducirse que la esencia es universal. A ello puede añadirse que, frente a la generación y corrupción del compuesto particular, Aristóteles establece el carácter ingenerado e incorruptible de forma y materia (Z 8). Desde esta perspectiva, también han sido numerosos los autores han dirigido su crítica contra las lecturas que defienden el carácter particular de las formas ${ }^{43}$.

${ }^{42} \mathrm{La}$ tesis de que las esencias aristotélicas son individuales más que universales o esencias-especie ha sido defendida por W. Sellars, \& R. Albritton, «Substance and Form in Aristotle», Journal of Philosophy, 22, 1957, pp. 698-708; E. Hartman, "Aristotle on the Identity of Substance and Essence», Philosophical Review, 85, 1976, pp. 545-561; R. Heinaman, "Aristotle's Thenth Aporia», Archiv für Geschichte der Philosophie, 61, 1979, pp. 249-270; M. Frede, «Substance in Aristotle's Metaphysics", Aristotle on Nature and Living Things, en Allan Gottheld (ed.), Pittsburg, 1985, pp. 17-26; Ch. Witt, Substance and essence in Aristotle, 1989, pp. 143-179.

${ }^{43}$ La más reciente crítica generalizada contra las tesis particularistas se encuentra en Th. Scaltsas, Substance and Universals in Aristotle's Metaphysics, Ithaca, 1994, particularmente el apéndice 3: «Against Individual Forms», pp. 229-251. Entre otros muchos especialistas, también se han posicionado contra la singularidad de las formas: M. J. Loux, «Form, Species and Predication in

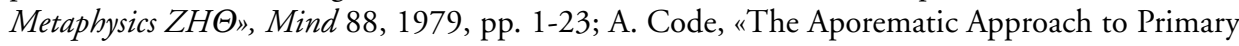
Being in Metaphysics Z», Canadian Journal of Philosophy, supp. vol. 10, 1984, pp. 1-20; J. Lear, 
¿Es posible explicar la incongruencia, real o aparente, de los contenidos de $Z$ ? En principio, todo aquel que intente armonizar la afirmación de que la substancia se identifica con la esencia y la afirmación de que el universal no es substancia, deberá tomar uno de estos dos caminos: o restringir el significado del término esencia, o restringir el significado del término universal ${ }^{44}$. Con respecto al primer camino, es muy difícil negar que en la mayor parte de $Z$ las formas o esencias son entendidas como formas-especie universales, en el sentido en que hombre expresa la esencia del hombre, lo que todo hombre es por sí. Pero junto a las formas-especie, en ciertas ocasiones parece darse también un reconocimiento de las formas o esencias particulares, como cuando se habla de la forma de Sócrates, que podría ser interpretado como algo que pertenece a Sócrates y a nadie más. Según lo expuesto, podría argumentarse que cuando se habla de substancias, Aristóteles se está refiriendo a estas últimas formas y no a las formas-especie. Un problema al que se enfrenta esta interpretación lo constituye el hecho de que los casos aducidos en apoyo de esta interpretación son muy escasos en comparación con el supuesto general que asume la aparente universalidad de las for$\mathrm{mas}^{45}$. Por otra parte, Aristóteles en ningún momento distingue explícitamente

The desire to understand, Cambridge, 1988, pp. 273-93; M. L. Gill, Aristotle on Substance, Princeton, 1989, pp. 31-34; M. J. Woods, "Universals and Particular Forms in Aristotles» Metaphysics", Oxford Studies in Ancient Philosophy, Supp. Vol., 1991, pp. 41-56; F. A. Lewis, Substance and Predication in Aristotle, Cambridge, 1991, pp. 309-48; M. J. Loux, Primary ousia, Ithaca, 1991, pp. 187-196; L. Spellman, Substance and Separation in Aristotle, Cambridge, 1995, pp. 40-62; y T. Oñate, Para leer la Metafisica de Aristóteles en el siglo XXI, Madrid, Dykinson, 2001, pp. 42-56.

${ }_{44}$ Para la exposición de esta cuestión sigo en parte el esquema de D. Bostock, Aristotle. Metaphysics. Books $\mathrm{Z}$ and $\mathrm{H}, 1994$, pp. 187-88.

45 Bostock, 1994, op. cit., pp. 187-88 ha recogido un grupo de indicios que podrían apoyar la singularidad de las formas: Z 15, $1039 \mathrm{~b} 25$ y menos claramente Z 4, 1029b14-15 y Z 6, 1032a8 parecen expresar el ser de una realidad particular; en Z 10, 1035a7-9, 1036a12-15 y 11, 1037a78 la cosa particular es identificada con su forma; en otros pasajes se indica que ciertas formas no necesitan ser eternas a pesar de no estar sujetas a los procesos de generación y corrupción: E 3, 1027a27-28; Z 10, 1035a28-30; E 15, 1039b22-27; $\Lambda$ 3, 1043b14-21; $\Lambda$ 3, 1070a15-17, etc. Finalmente, el término tòde ti ha sido interpretado en ocasiones como sinónimo de particular. Como afirma el propio Bostock, la mayoría de estos indicios son poco consistentes. No obstante, hay un fragmento de Met. $\Lambda$ donde Aristóteles parece establecer explícitamente la particularidad de las formas: «... las causas y los principios son distintos para cosas distintas que no pertenecen al mismo género (...). Y para las cosas de la misma especie son distintas, pero no específicamente, sino que son distintas individualmente: tu materia, tu forma y lo que en tu caso produce el movimiento y los míos, si bien son los mismos universalmente hablando». Al margen de las explicaciones que puedan darse, la afirmación es bastante explícita. 
las dos supuestas clases de formas —universales las unas, particulares las otras-, sino que reúne a todas bajo un mismo término. En todo caso, aun admitiendo que Aristóteles acepta la particularidad de las formas, seguiría sin resolverse el problema de la incongruencia de Z 13 con el resto del tratado.

Así pues, si las formas deben entenderse en su sentido habitual — como universales-, el camino para intentar armonizar la afirmación de que la substancia se identifica con la esencia y la de que el universal no es substancia consistirá en rebajar la segunda afirmación argumentando que el uso del término universal en Z 13 no es el habitual, y que el término adquiere un sentido mucho más limitado ${ }^{46}$. Sin embargo, ello entra en conflicto con lo expresado numerosas ocasiones en el texto: que nada que se predique universalmente puede ser considerado substancia ${ }^{47}$.

Una posible solución a la intrincada aporía sobre la singularidad o universalidad de la forma consiste en negar la disyunción y aceptar que la forma específica o substancia cumple las propiedades de los singulares en lo referente a su condición de substancia, y las propiedades de los universales en lo referente a su condición de objeto de conocimiento ${ }^{48}$. Pero, de cualquier modo, el filósofo no ha dado respuesta positiva a la cuestión. El desarrollo euporético desplegado por Aristóteles en los libros $\mathrm{Z}$ y H, aun siendo notablemente más complejo que el desarrollo diaporético de B 6 , no ha satisfecho plenamente su objetivo, lo que nuevamente muestra que los procesos diaporético y euporético constituyen procesos distintos y autónomos.

${ }^{46}$ M. J. Woods, «Problems in Metaphysics Z, Chapter 13», en Moravcsik, Aristotle. A Colection of Critical Essays, Nueva York, Doubleday, 1967, pp. 216 afirma: Aristotle was in fact maintaining that only some things properly described as kathólou are to be regarded as ousia; something kathólou is ousia, only if it is not predicated universally. Woods acepta, por lo tanto, que los universales predicados universalmente no son substancias, pero afirma asimismo que las formas-especie no se predican universalmente, por lo que éstas no entrarían dentro de la restricción aristotélica de Z 13. Una versión de este argumento se encuentra en Loux, 1979, op. cit., Code, 1984, op. cit. y Lewis, 1991, op. cit., quienes defienden que las formas-especie no son predicadas de los miembros particulares de su especie, sino solamente de su materia. Por su parte, Lear, 1988, op. cit. interpreta que en el contexto de Z 13 universal se refiere solamente a aquello ente más universal que las indivisibles formas-especie.

${ }^{47}$ Cf. por ejemplo, Z 13, 1038b9, 15, 35, Z 16, 1040b23, 1041a4, H 1, 1042a21, I 2, 1053b16-17.

48 Solución ensayada por J. Owens, «La forma aristotélica como causa del ser», Revista de Filosofía, 1977, pp. 267-287 y Oñate, 2001, op. cit., pp. 45-52. 


\section{Conclusiones}

El vínculo entre dialéctica y filosofía primera en la Metafísica es un vínculo estrecho. Ello se pone de manifiesto en la importante presencia de procedimientos dialécticos a lo largo de la obra, entre los que encontramos la revisión histórica de la filosofía prearistotélica expuesta en el libro A, la demostración refutativa del PNC en $\Gamma 4$ y el desarrollo diaporético en B 2-6.

Aun valorando la importante presencia de los procedimientos dialécticos en la constitución de la filosofía primera, su método no puede identificarse con la dialéctica, pues la fase euporética, identificada con la búsqueda positiva de la solución, constituye una fase mucho más compleja, no dialéctica, que va más allá de lo establecido en el desarrollo diaporético. Ello se pone de manifiesto en la gran complejidad conceptual y doctrinal de las soluciones aportadas por el Estagirita a las aporías planteadas en $\mathrm{B}$.

Independientemente del desarrollo diaporético, la búsqueda de la solución o fase euporética puede darse o no darse de un modo completo, tal como se pone de manifiesto en el análisis de las soluciones ensayadas por el Estagirita a propósito de algunas aporías. Como ejemplo de todo ello, cabe presentar la fase euporética de las aporías undécima (sobre la naturaleza de lo uno y lo ente), cuyo objetivo es plenamente satisfecho, y la decimoquinta (sobre la naturaleza particular o universal de la forma substancial), cuyo objetivo no es plenamente satisfecho. Ello muestra que los procesos diaporético y euporético constituyen procesos distintos y autónomos.

\section{Bibliografía}

Aguirre, J. (2007). La aporía en Aristóteles. Libros B y K 1-2 de la Metafísica, Madrid. Aubenque, P. (1962). Le probleme de l'être chez Aristote, París.

- (2009). Problemes aristotèliciennes, París.

BARNES, J. (1975). «Aristotle's theory of demostration», Articles on Aristotle, Cambridge, pp. $65-87$.

- (1980). "Aristotle and the methods of ethics», Revue internationale de Philosophie, XXXIV, pp. 490-511. 
BERTI, E. (1965). L'Unitá del sapere in Aristotele, Padua.

- (1970). «La dialettica in Aristotele», L'attualitá della problematica aristotelica. Atti del convegno franco-italiano su Aristotele (Padova, 6-8 aprile 1967), Padova, pp. 3380. (Reimpreso en Berti, E. (1975). Studi aristotelici, L'Aquila, pp. 109-133).

- (1979). «Le Probléme de la substantialité de l'être et de l'un dans la Métaphysique», en P. Aubenque ed. Études sur la Métaphysique d'Aristote, Actes du VI Symposium Platonicum, París, pp. 89-129.

— (1980). «Aristote et la méthode dialectique du «Parmenide» de Platon», Revue internationale de Philosophie, XXXIV, 1980, pp. 341-358.

- (2007). «L'essere e l'Uno in Metaph. B», en V. Celluprica ed., op. cit., pp. 103-126

- (2008). Dialectique, physique et métaphysique. Études sur Aristote, Lovaina.

Bostock, D. (1994). Aristotle. Metaphysics. Books Z and H. Oxford.

Calvo, T. (1984). Aristóteles. Metafísica, Madrid.

CellupricA, V. ed. (2003). Il libro B della Metafisica di Aristotele, Roma.

Cleary, J. (1995). Aristotle and Mathematics: Aporetic Method in Cosmology and Metaphysics, Leiden.

Code, A. (1984). "The Aporematic Approach to Primary Being in Metaphysics Z», Canadian Journal of Philosophy, supp. vol. 10, pp. 1-20.

Couloubaritsis, L. (1978-1979). «Dialectique et philosophie chez Aristote», Philosophia VIII-IX, pp. 229-256.

- (1983). «L'Étre et l'un chez Aristote (I y II)», Revue de philosophie ancienne I, pp. 49-98 y $143-195$.

Croissant, J. (1986). "La dialectique chez Aristote», en J. Croissant ed. Études de philosophie ancienne. Bruselas, pp. 161-185.

Evans, J. D. G. (1977). Aristotle's conception of dialectic, Cambridge.

Frede, M. (1985). «Substance in Aristotle's Metaphysics», en Gottheld, A. ed. Aristotle on Nature and Living Things, Pittsburg, pp. 17-26.

GILL, M. L. (1989). Aristotle on Substance, Princeton.

Hartman, E. (1976). "Aristotle on the Identity of Substance and Essence», Philosophical Review 85, pp. 545-561.

Heinaman, R. (1979). "Aristotle's Thenth Aporia», Archiv für Geschichte der Philosophie 61, pp. 249-270. 
IRWIN, T. H. (1976-1977) «Aristotle's discovery of Metaphysics», The review of metaphysics XXXI, pp. 210-229.

KunG, J. (1986). "Aristotle on "being is said in many ways"», History of Philosophy Quaterly 3, pp. 3-18.

LEAR, J. (1988). The desire to understand, Cambridge.

Le Blond, J. M. (1939). Logique et methode selon Aristote, París.

LESZL, W. (1970). Logic and metaphysics in Aristotle, Padua.

LESZL, W. (1975). Aristotle's conception of ontology, Padua.

LEWIS, F. A. (1991). Substance and Predication in Aristotle, Cambridge.

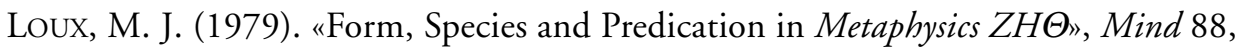
pp. 1-23.

- (1991). Primary ousia, Ithaca.

LugarinI, L. (1959). «Dialettica e filosofia in Aristotele», Il Pensiero 4, pp. 48-69.

- (1961). Aristotele e l'idea della filosofia, Florencia, 1961 (2. ${ }^{a}$ ed. 1972).

Madigan, A. (1999). Metaphysics: Books B \& K 1-2, Oxford.

MotTe, A. \& Rutten, Chr. eds. (2001). Aporia dans la philosophie grecque des origines à Aristote, Louvain-La-Neuve.

Oñate, T. (2001). Para leer la Metafisica de Aristóteles en el siglo XXI, Madrid.

Owen, G. E. L. ed. (1968). Aristotle on dialectic. The Topics. Proceedings of the third symposium aristotelicum. Oxford.

Owens, J. (1977). «La forma aristotélica como causa del ser», Revista de Filosofía, pp. 267-287.

Perelman, Ch. (1952). «Dialectique et dialogue», Hermeneutik und Dialektik. Tubinga, pp. 77-83.

- (1958). Rhétorique et philosophie. Pour une théorie de l'argumentation en Philosophie. París.

Reale, G. (1995). Aristotele. La Metafisica, Milán.

RegIS, L. M. (1935). L'opinion selon Aristote, París.

Ross, W. D. (1997). Aristotle’s Metaphysics, Oxford (1. ${ }^{a}$ ed. 1924). 
Rossitto, C. (1993). «La dialettica e il suo ruolo nella Metafisica di Aristotele», Rivista de filosofia neo-scolastica, LXXXV, pp. 370-424.

- (2000). Studi sulla dialettica in Aristotele, Nápoles.

SCALTSAS, Th. (1994). Substance and Universals in Aristotle's Metaphysics, Ithaca.

Sellars, W. \& Albritton, R. (1957). «Substance and Form in Aristotle», Journal of Philosophy 22, pp. 698-708.

Sichirollo, L. (1963). Giutificazzioni della dialettica in Aristotele. Urbino.

- (1965). Storicità della dialettica antica. Padua.

- (1973). La dialettica, Milán.

Spellman, L. (1995). Substance and Separation in Aristotle, Cambridge.

Trendelenburg, F. A. (1994). La dottrina delle categorie in Aristotele, Milán, (1. a ed. alemana, 1846).

Vianno, C. A. (1958). «La dialettica in Aristotele», Rivista di Filosofia 49, pp. 154-178.

VV. AA. (1970). L'attualitá della problematica aristotelica. Atti del convegno franco-italiano su Aristotele (Padova, 6-8 aprile 1967), Padova.

WeIL, E. (1951). «La place de la logique dans la pensée aristotèlicienne», Revue de Métaphisique et de morale.

WitT, Ch. (1989). Substance and essence in Aristotle. Cornell.

Woods, M. J. (1967). «Problems in Metaphysics Z, Chapter 13», en Moravcsik, J. M. E. Aristotle. A Colection of Critical Essays, Nueva York.

Woods, M. J. (1991). «Universals and Particular Forms in Aristotles' Metaphysics», Oxford Studies in Ancient Philosophy, Supp. Vol., pp. 41-56.

Recibido: $17 / 08 / 2010$

Aceptado: 22/10/2010 